\title{
Correction: Moderated Online Social Therapy for Young People With Active Suicidal Ideation: Qualitative Study
}

Eleanor Bailey ${ }^{1,2,3}$, BA; Jo Robinson ${ }^{1,3}$, BSc, MSc, PhD; Mario Alvarez-Jimenez ${ }^{1,3}$, BSc, MResMeth, DClinPsy, PhD; Maja Nedeljkovic ${ }^{2}$, MPH, MPsych(Clin), PhD; Lee Valentine ${ }^{1,3}$, BA, MSocWk; Sarah Bendall ${ }^{1,3}$, PGDipClinPsych, $\mathrm{PhD}$; Simon D'Alfonso ${ }^{1,4}$, BASc, PhD; Tamsyn Gilbertson ${ }^{1,3}$, MSc, MPsych(Clin); Ben McKechnie ${ }^{1}$, BA, MPsych(Clin); Simon Rice ${ }^{1,3}$, MPsych(Clin), PhD

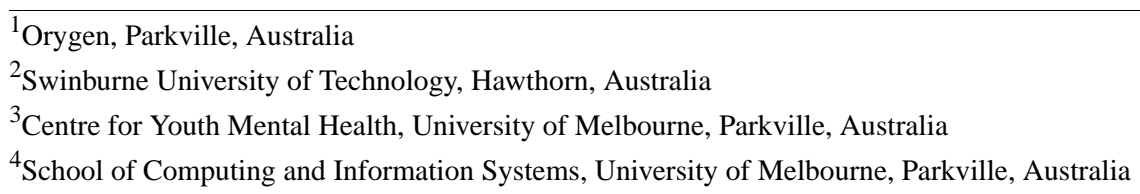

Corresponding Author:

Eleanor Bailey, BA

Orygen

Locked Bag 10

35 Poplar Road

Parkville, 3052

Australia

Phone: 610412483600

Email: eleanor.bailey@orygen.org.au

\section{Related Article:}

Correction of: https://www.jmir.org/2021/4/e24260

(J Med Internet Res 2021;23(6):e29645) doi: 10.2196/29645

In "Moderated Online Social Therapy for Young People With Active Suicidal Ideation: Qualitative Study" (J Med Internet Res 2021;23(4):e24260), the authors noted one error.

Incorrect qualifications were provided for author Ben McKechnie. The original qualifications provided were: BA, MPsych(Clin), MClinFamTher. However, MClinFamTher was provided in error and has been removed.
The correction will appear in the online version of the paper on the JMIR website on June 10, 2021, together with the publication of this correction notice. Because this was made after submission to PubMed, PubMed Central, and other full-text repositories, the corrected article has also been resubmitted to those repositories.

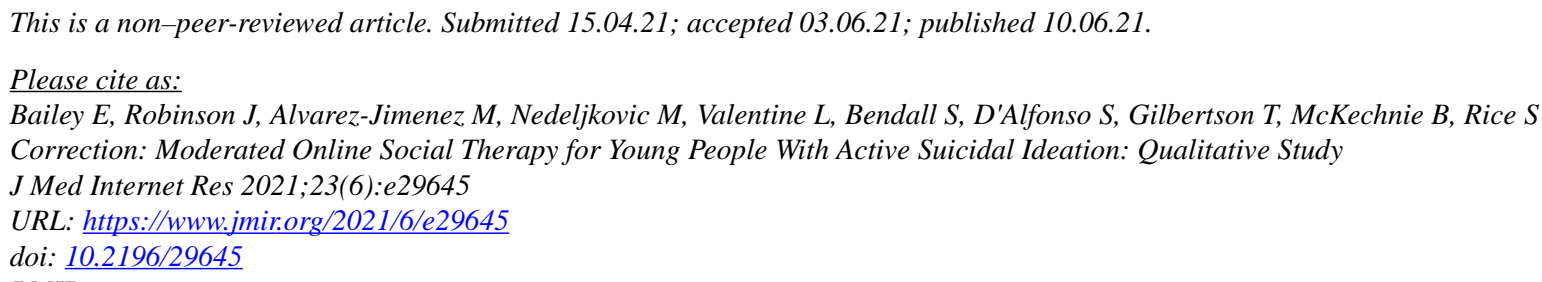

(CEleanor Bailey, Jo Robinson, Mario Alvarez-Jimenez, Maja Nedeljkovic, Lee Valentine, Sarah Bendall, Simon D'Alfonso, Tamsyn Gilbertson, Ben McKechnie, Simon Rice. Originally published in the Journal of Medical Internet Research (https://www.jmir.org), 10.06.2021. This is an open-access article distributed under the terms of the Creative Commons Attribution License (https://creativecommons.org/licenses/by/4.0/), which permits unrestricted use, distribution, and reproduction in any medium, provided the original work, first published in the Journal of Medical Internet Research, is properly cited. The complete 
bibliographic information, a link to the original publication on https://www.jmir.org/, as well as this copyright and license information must be included. 